\title{
DESCONSTRUÇÕES ESTRATÉGICAS PARA ABORDAGENS QUALITATIVAS: O BINARISMO E AS PERCEPÇÕES DO OUTRO
}

\section{STRATEGIC DECONSTRUCTIONS FOR QUALITATIVE APPROACHES: BINARISM AND PERCEPTIONS OF OTHERS}

\author{
Guilherme Bergo Leugi ${ }^{1}$ \\ Cátia Regina Muniz ${ }^{2}$ \\ Giovanni Moura de Holanda ${ }^{3}$ \\ Angela Maria Alves ${ }^{4}$
}

\begin{abstract}
Resumo: A discussão ora apresentada nasceu de um projeto de pesquisa conduzido no âmbito de um laboratório multidisciplinar para desenvolvimento de metodologias e sistemas de avaliação de políticas públicas e corporativas, produto de interlocuções multidisciplinares. O trabalho apresenta fundamentos epistemológicos e metodológicos para compreender populações marginalizadas e suas demandas para políticas públicas do ponto de vista de uma análise contextual baseada nos princípios da desconstrução e outras ferramentas de análise qualitativa. $\mathrm{O}$ texto recupera definições basilares da formação de construtos sociais por meio de lógicas binárias, expõe alternativas para enfrentá-las e questioná-las, especialmente considerando a desconstrução, a teoria Queer, o rizoma, o interacionismo simbólico e a análise contextual social. Ao final são traçadas implicações para superar criativamente o vácuo deixado por uma abordagem desconstrucionista.
\end{abstract}

Palavras-chave: Desconstrução; Abordagens qualitativas; Metodologias de análise; Epistemologia; Políticas públicas.

\begin{abstract}
The present discussion was prompted from research conducted within a multidisciplinary laboratory for the development of methodologies and systems for the evaluation of public and corporate policies, as a product of multidisciplinary debates. The paper presents epistemological and methodological foundations to understand marginalized populations and their necessities regarding public policies, from the perspective of a contextual analysis based on the principles of deconstruction and other tools of qualitative analysis. The text dwells on basic definitions of the formation of social constructs through a binary logic, suggests alternatives to face and question such logic, especially considering deconstruction, Queer theory, rhizome, symbolic interactionism, and social contextual analysis. In conclusion, implications are drawn to creatively overcome the vacuum left by a deconstructionist approach.
\end{abstract}

Keywords: Deconstruction; Qualitative approaches; Methodologies of analysis; Epistemology; Public policies.

\footnotetext{
${ }^{1}$ Doutor pela University of South Australia (UniSA). Centro de Tecnologia da Informação Renato Archer (CTI), Campinas, São Paulo, Brasil. E-mail: guilherme.leugi@cti.gov.br

${ }^{2}$ Doutora pela Universidade Estadual de Campinas (Unicamp). Centro de Tecnologia da Informação Renato Archer (CTI), Campinas, São Paulo, Brasil. E-mail: catia.muniz@cti.gov.br

${ }^{3}$ Mestre pela Universidade Estadual de Campinas (Unicamp). Centro de Tecnologia da Informação Renato Archer (CTI), Campinas, São Paulo, Brasil. E-mail: giovanni.holanda @cti.gov.br

${ }^{4}$ Doutora pela Universidade de São Paulo (USP). Centro de Tecnologia da Informação Renato Archer

(CTI), Campinas, São Paulo, Brasil. E-mail: angela.alves@ cti.gov.br
} 


\section{Contexto e apresentação}

A discussão ora apresentada nasceu de um projeto de pesquisa conduzido no âmbito de um laboratório multidisciplinar para desenvolvimento de metodologias e sistemas de avaliação de políticas públicas e corporativas. Tal projeto se insere em um contexto mais amplo de pesquisa e, desse modo, ao propor uma metodologia de avaliação de condições de integração em suas comunidades de mulheres egressas do cárcere, a condução do trabalho tem sempre no horizonte a perspectiva de inovar no campo da avaliação de políticas públicas, sejam inovações teóricas, metodológicas ou técnicas.

O presente artigo é produto das interlocuções ocorridas entre pesquisadores da equipe multidisciplinar, ao delinearem o escopo da abordagem analítica do trabalho de compreensão das condições de integração comunitária de egressas da prisão, conduzindo a reflexões para além do trabalho pontual de desenvolvimento de ferramentas metodológicas no trabalho. Desse modo, trata-se aqui não de explicitar a metodologia de avaliação que foi desenvolvida em sua totalidade, mas expor uma estratégia de análise com implicações metodológicas que transcendem à abordagem específica dentro da qual a estratégia nasceu, tornando possível expandir a análise a outras investigações e outras populações também consideradas à margem da sociedade. Este é um ensaio sobre desafios técnicos e teóricos sobre o estudo em profundidade e contextual de populações marginalizadas, com vistas a produção de subsídios para profissionais e pesquisadores em políticas públicas.

A metodologia de avaliação que informou a estratégia de análise aqui explicitada foi construída sob influência da concepção de metodologias líquidas (ALVES; HOLANDA, 2016) para lidar com sistemas complexos. Ao referirem-se à fluidez metodológica, os autores fazem uma analogia à modernidade líquida de Zygmunt Bauman (2000). Assim, como os fluidos, que se moldam aos seus recipientes ou contextos, combinar diferentes técnicas e métodos, e também abordagens analíticas e de interpretação produz novas possibilidades de apreensão dos fenômenos de interesse (ALVES; HOLANDA, 2016). Desse modo, metodologias líquidas procuram olhar, por exemplo, para políticas públicas de modo integral, refletindo a complexidade dos sistemas em que tais políticas se inserem e sobre os quais impactam. A análise decorrente da aplicação dessa abordagem metodológica é, portanto, contextual e sistêmica. A liquidez metodológica também abre espaço para (re)utilização do que foi construído em um contexto para outro, desde que adaptado. 
Ao conduzir pesquisa visando à inovação metodológica na avaliação de políticas públicas a equipe multidisciplinar foi levada a incluir em suas análises as concepções e formações das situações e percepções sociais de 'marginalidade', 'diferença', ou ainda 'estranhamento'. Tal inclusão foi necessária devido aos contextos específicos da população estudada. Contudo, para a reflexão deste ensaio, mulheres egressas do cárcere constituem, por suas experiências, um 'caso exemplar' e um ponto de vista privilegiado para estudar o funcionamento de políticas públicas in loco (MUNIZ; LEUGI, 2018; MUNIZ; LEUGI; ALVES, 2017). No processo de análise, os contextos específicos nos mostram um primeiro plano de um panorama vigente de atitudes que marginalizam, diferenciam ou estranham tais sujeitos ou grupos. Assim, o olhar originalmente lançado sobre o sistema prisional e a egressa desse sistema é transformado, neste ensaio e sob certo aspecto, de idiográfico para nomotético.

Como já sugeriu Radcliffe-Brown (1952), investigações acerca dos fenômenos humanos podem tanto traçar princípios gerais, em uma abordagem nomotética, quanto focalizar esforços na descrição de aspectos particulares e subjetivos de um dado cenário, caracterizando uma abordagem idiográfica (KUPER, 1977). Não se trata de encontrar princípios gerais, mas aspectos generalizáveis acerca de populações que, aí sim, apresentam certas especificidades.

Dessa maneira, a proposta do presente artigo é discutir algumas possibilidades de produção social da marginalização e do estranhamento e como essa produção interfere na coleta e análise de dados de natureza subjetiva, estabelecendo para tal uma aproximação, para identificação de similitudes que podem trazer elementos úteis à abordagem proposta, entre a teoria Queer, as ideias de Derrida sobre desconstrução e o conceito de rizoma de Deleuze e Guattari. As razões para a seleção dessas abordagens e a forma como podem ajudar a compreender os fenômenos de interesse serão tratadas ao longo do texto.

\section{Estigma, marginalização e formulações binárias}

Considerando a população encarcerada e egressa da prisão como exemplo que serve de iniciador para a discussão e compreensão da marginalização, temos o que segue. A população encarcerada é alvo e produto de processos transversais de marginalização, usualmente carregando também os estigmas criados nesse percurso (COSTA, 2011; GUIMARÃES, 2006; MASSARO, 2014, entre outros). Criam-se estereótipos, preconceitos, ou percepções sociais que dificultam sua inserção social fora da 
criminalidade e reduzem possibilidades reais de trabalho, renda, educação e dignidade antes da prisão e após conseguir a liberdade, seja ela condicional, provisória ou definitiva.

Como premissa, é sugerido aqui que essas percepções são produzidas, ao menos parcialmente, por formulações e compreensões binárias. Tal produção seria similar à de outras noções de oposição binária como 'pessoas que agem dentro da lei' e 'pessoas que agem fora da lei'; 'cidadão honesto' e 'marginal'; 'homem' e 'mulher'; entre outros. Há outros aspectos relacionados a tais dicotomias, que operam em várias esferas da sociedade, por exemplo, classe, discriminação racial (institucionalizada ou não), diferentes atribuições psicossociais feitas com base em estereótipos de nacionalidade. Aqui, contudo, o foco é apenas na estrutura do pensamento discriminatório, em termos dessa propriedade fundamental nele identificada: o binarismo que posiciona 'nós' como diferentes dos 'outros'.

A partir dessa premissa, apresentamos a construção de um arcabouço analítico para a compreensão da caracterização de populações vistas à margem, como estranhas ou diferentes; caracterizações essas baseadas especialmente na formulação de categorias sociais usualmente utilizadas no discurso vigente. Por exemplo: 'infrator', 'criminoso', 'honesto'. A fim de empreender tal construção reunimos 'tijolos' da teoria Queer, das ideias de desconstrução iniciadas por Derrida e o do modelo rizomático de Deleuze e Guattari.

Procuramos contemplar os principais fundamentos de ambas as abordagens, a fim de dar conta da compreensão dos fenômenos estudados de maneira mais abrangente e contextual. Sob essa ótica, os conceitos serão tratados em seu contexto social, o que habilita o investigador a desconstruí-los e (re)construí-los.

Para explicitar o fio condutor das formulações binárias, estruturamos o ensaio da seguinte forma: primeiramente, será apresentado como Durkheim, Mauss e Hertz já discutiam a lógica de várias sociedades em classificar as 'coisas do mundo' por meio de oposições binárias; em seguida, serão discutidas algumas ideias de Derrida acerca da desconstrução; após isso, será apresentado o rizoma deleuziano; depois, a teoria Queer; e, por fim, será exposta uma possibilidade de relação entre todos pontos vista de modo a pensar contextualmente as condições de populações à margem, minoritárias ou estigmatizadas. 


\section{Os binarismos e as classificações sociais: Aspectos sociológicos e antropológicos}

Durkheim e Mauss em Algumas Formas Primitivas de Classificação propõem que as estruturas de classificação lógicas são baseadas em estruturas de classificação social. A premissa proposta seria válida não só para as estruturas de classificação, mas também para "outras funções ou noções fundamentais do entendimento" (DURKHEIM; MAUSS, 2000, p. 203).

Para fundamentar a premissa defendida, os autores apresentam uma apreciação de sistemas classificatórios encontrados no continente australiano, por exemplo, nas sociedades ou etnias Arrernte e Dardi-Dardi ${ }^{5}$. Para Durkheim e Mauss, a organização social em duas fratrias principais e clãs traduzem a forma como essas sociedades classificam o mundo, ou seja, "a classificação das coisas reproduz a classificação dos homens [sic]". "Todas as coisas estão dispostas em duas categorias que correspondem às duas fratrias", ou seja, são classificadas por oposições binárias (DURKHEIM; MAUSS, 2000, p.184-185). Ambas fratrias ainda podem ser e usualmente são divididas em subfratrias, formando um sistema complexo de categorias e subcategorias para todas as entidades do universo. Isso se aplica tanto às entidades conhecidas como às entidades que ainda serão conhecidas, pois pertencimento às fratrias é um dado 'natural' dessa visão de mundo.

O ponto principal do ensaio sobre as formas de classificação é apontar que um sistema classificatório tão disseminado, ao ser identificado, deve servir também para iluminar o conhecimento acerca das operações lógicas sociais para vários grupos humanos e não apenas para aqueles que historicamente habitam o continente australiano. A organização social, neste ponto de vista, é subjacente e a priori em relação à organização do universo e das coisas nele contidas. Essa organização social ecoa modos de afetação da sensibilidade da comunidade e, nesse sentido, é possível pensar "a história da classificação científica" como "a própria história das etapas no curso das quais este elemento de afetividade social se enfraqueceu" (DURKHEIM; MAUSS, 2000, p.202203) ou se modificou, como é da perspectiva do presente artigo.

A compreensão de sistemas de pensamento assentados em binarismos pode auxiliar na compreensão de outros sistemas de categorização social binária, inclusive no do sistema prisional, âmbito no qual o exercício teórico aqui apresentado foi gestado.

\footnotetext{
${ }^{5}$ Durkheim e Mauss usam Arunta e Ta-ta-thi, respectivamente, que hoje são termos em desuso.
} 
Mantendo em mente o contexto relativo das abordagens aqui apresentadas, podemos, então, ponderar sobre as organizações sociais em fratrias que as 'coisas do mundo' são originalmente dividas segundo um critério específico, por exemplo, 'sagrado' versus 'profano', ou ainda 'puro' versus 'impuro'. Essa divisão, no sentido de como ela é percebida pelo grupo social que a sustenta, é o "caráter dominante na classificação" (DURKHEIM; MAUSS, 2000, p. 201).

Os clãs também se agrupam, segundo os autores, de acordo com tais divisões que, por sua vez, aparecem representadas em seus totens. Devido à importância do totem para o grupo, é em função dele que o grupo organiza as demais entidades do universo. Essa organização, contudo, não trata necessariamente da regulação de conduta ou justificação de práticas cotidianas. A prescrição de matrimônio, por exemplo, aparece pela relação entre subfratrias, mais do que pela fratrias.

Assim, as primeiras categorias lógicas foram categorias sociais, isto é, classes de pessoas, nas quais as coisas foram inseridas. As 'coisas do mundo' colocadas sob esta perspectiva das divisões sociais, foram então organizadas a ponto de que não seria possível mais distinguir os grupos sociais e os grupos de 'outros seres' ou 'coisas'. "As coisas eram tidas como fazendo parte integrante da sociedade, e era o seu lugar na sociedade que determinava seu lugar na natureza" (DURKHEIM; MAUSS, 2000, p. 199).

Dessa forma, as classificações das coisas tiveram um caráter social e referiam-se às metades opostas em que as fratrias se organizavam. Na mesma perspectiva, de que o caráter social das classificações é anterior ao caráter natural ou físico, Hertz (1980) em A preeminência da mão direita: Um estudo sobre a polaridade religiosa, destaca que o dualismo era o cerne do pensamento chamado, até então, de primitivo e era esse dualismo que estruturava essas sociedades. As duas metades ou fratrias, às quais Durkheim e Mauss se referiram, e que tinham papel central na estrutura social dos grupos, eram mutuamente opostas como o sagrado e o profano. Tudo que figurava como pertencente a uma fratria - seus totens - era considerado sagrado e proibido para as pessoas que pertenciam a tal fratria; essas mesmas entidades do universo eram consideradas profanas pelas pessoas da outra fratria. Nas sociedades ocidentais esse dualismo passa a ter condição hierárquica rígida: "ao invés de clãs separados [...], aparecem castas ou classes, das quais uma, no topo, é essencialmente sagrada, nobre ou devotada a trabalhos superiores, enquanto outra, embaixo, é profana ou suja e ocupada com tarefas vis" (HERTZ, 1980, p. 106). Dessa maneira, haveria de um lado um polo da força, do bem e da vida, e de outro teríamos o polo da fraqueza, do mal e da morte. 
Segundo Hertz, "a polaridade social é um reflexo e uma consequência da polaridade religiosa" (1980, p. 106), isto é, em certas sociedades existe um agrupamento de características do que é sagrado, nobre e precioso, e outro do que é profano e comum, "ou em duas palavras, um lado direito e um lado esquerdo" (HERTZ, 1980, p. 108). Assim, tanto Durkheim e Mauss como Hertz observam que as sociedades podem construir suas categorias a partir de oposições binárias.

Lévi-Strauss (2006) também havia apontado que a prevalência de sistemas binários, como o das fratrias, em várias sociedades, de diferentes escalas em termos populacionais, apontam para algo estruturante das sociedades, e que ao estudar fratrias "nós podemos fazer um tipo de arqueologia social. Compreender como um sistema de fratrias tem poder sobre seus membros é como escavar a pré-história de humanidade em uma área nunca alcançada por pás e picaretas” (DOUGLAS, 2002, p. 169, tradução livre). Mary Douglas insiste que é importante colocar a compreensão do poder das fratrias em perspectiva. De nada valeria compreender a importância desses sistemas binários em suas sociedades de origem se não houver uma transposição dessa compreensão para nossas próprias sociedades (DOUGLAS, 2002). Não transpor esse conhecimento acabaria por contribuir para a criação de preconceitos epistemológicos, e mesmo sociais, na direção do 'nós' e 'outros', o que seria um problema tanto teórico quanto de posicionamento metodológico e sensibilidade cultural (por exemplo, CALLIOU, 1998). Já que, em alguma medida, implicada nas definições de quem somos nós e quem são os outros, está a noção de quem é humano e quem não é humano, respectivamente (por exemplo, PHILOGÈNE, 2007, p. 32). Aceitar que as formulações binárias são comumente encontradas não significa adotá-las como verdadeiras. Pelo contrário, trata-se de observar processos de formação de pensamento e, então, contextualizá-los.

\section{Desconstruções epistemológicas dos binarismos}

Até aqui destacamos principalmente de como certas sociedades não ocidentais organizam-se ao redor de operações binárias que, então, são estendidas para o mundo em que habitam. Expandindo essa premissa, Derrida (1991) propõe que a lógica ocidental opera também por binarismos nos quais um termo é entendido sempre como superior, à medida que o outro é o seu derivado, inferior (LOURO, 2001). A hierarquia conceitual produzida pela oposição binária seria, portanto, um problema a ser superado. Esse é um dos sentidos em que a ideia de desconstrução aparece em Derrida. A hierarquia conceitual 
é uma questão restrita ao discurso e a ação de investigadores em relação a essa hierarquia posta. Assim, ao empreender um processo de desconstrução, pesquisadores devem procurar "minar, escavar, perturbar e subverter os termos que afirma e sobre os quais o próprio discurso se afirma" (LOURO, 2001, p. 548). Derrida ainda sugere que os binários sustentadores da filosofia ocidental, deveriam passar por um processo de desconstrução que não se resumisse a "passar de um conceito para outro, mas em modificar e em deslocar uma ordem conceitual assim como a ordem não-conceitual à qual se articula" (DERRIDA, 1991, p. 372). O processo de desconstrução é uma reversão estratégica que desordena os pares que definem certa estrutura de pensamento (LOURO, 2001).

Em perspectiva similar, visando o abandono das estruturas binárias para a construção de conhecimento, Deleuze e Guattari (2005) propõem a construção de pensamento de modo 'múltiplo'. A noção norteadora da abordagem crítica dos autores, para compreender como o pensamento pode ser produzido de modo múltiplo é o rizoma. Em um rizoma, ao contrário, por exemplo, de uma raiz pivotante, todas as partes são funcionalmente equivalentes. Partes do rizoma podem funcionar como raiz ou como ramo, independentemente de sua posição, ou seja, de seu lugar hierárquico ou geográfico em relação a um eixo ou centro. Assim, partindo da analogia com tais noções biológicas os dois autores definem que rizoma é um sistema aberto (DELEUZE; GUATTARI, 2005). Ademais, um sistema é formado por conceitos “e, é um sistema aberto quando os conceitos se relacionam com as circunstâncias em vez de essências" (DELEUZE, 1995, p. 32, tradução livre).

Definir aspectos centrais do rizoma e subsumi-lo a um conjunto de parâmetros pontuais seria uma contradição em relação à construção da abordagem teórica de Deleuze e Guattari, na qual se pretende promover a construção não-hierarquizada e descentralizada de pensamento. Contudo, é possível considerar as seis características do rizoma (DELEUZE; GUATTARI, 2005), conforme definido em Mil platôs.

Qualquer ponto de um rizoma pode ser conectado a qualquer outro, e é necessário que o seja, o que expressa a primeira e segunda propriedades do rizoma: conexão e heterogeneidade, respectivamente. Ao invés de partir de um ponto ou princípio central e depois desenvolver-se por dicotomias, o rizoma apresenta suas partes em 'agenciamentos coletivos', sem hierarquias. A terceira propriedade é a da multiplicidade. A multiplicidade no rizoma significa que não há centralização de conceitos, e todos são hierarquicamente equivalentes. A multiplicidade, característica do rizoma, não tem unidade ou ponto 
central, "não tem sujeito ou objeto, apenas determinações, magnitudes e dimensões" (DELEUZE; GUATTARI, 2005, p. 8).

Em quarto lugar aparece a propriedade de que o rizoma pode ser quebrado em várias de suas regiões, sem que necessariamente isso abale a organização rizomática ('ruptura a-significante'). Essa organização também pode ser refeita a partir de qualquer ponto resultante da ruptura, sem grandes perdas. A quinta e sexta propriedades são enunciadas como cartografia e decalcomania, respectivamente. Trata-se de compreender que o rizoma não é fundamentado em ideias centrais, 'eixo genético', ou 'estrutura profunda'. Quando se tem a construção de uma forma de pensamento baseada em ideias pivotantes, isso produziria os decalques de algo que já está feito. As ideias satélites seriam fortemente definidas por sua relação com as ideias centrais em termos das primeiras 'decalcando' ou 'reproduzindo' as segundas, ainda que em dimensões diferentes. O rizoma, ao contrário, é um mapa e não se justifica em rastreamentos e decalques (DELEUZE; GUATTARI, 2005).

É importante mencionar, contudo, que não se trata de substituir um modelo por outro. Não se trata de substituir um modelo binário de construção de conhecimento por um 'modelo' rizomático. O rizoma é uma explicação, uma descrição do processo de formação de conceitos, e não uma prescrição. Substituir um modelo binário por um modelo rizomático vai na contramão da proposição deleuziana. Afinal, Deleuze, "ao invés de oferecer mais um sistema de termos e ideias", estava muito mais interessado em "expressar o dinamismo e instabilidade do pensamento" (COLEBROOK, 2002, p. 4, tradução livre).

Souza (2012) ressalta que na concepção de Deleuze e Guattari, as potencialidades dos objetos em um rizoma apenas se realizam em encontros com outros objetos - em suas conexões -, o que promove um enfraquecimento da visão tripartida entre diferentes estratos de realidade: realidade, mundo e representação. A divisão do mundo em diferentes estratos não é um problema novo na filosofia. Dentre vários outros, Bentley (1945a, b) já apontava para a complicação epistemológica que advém de forçar uma divisão artificial entre as pessoas e suas representações (ou linguagem). O objeto que se apresenta de um modo é analisado em partes separadas, e isso obriga o investigador a gastar seu tempo construindo pontes que conectem partes do objeto que só foram separas pela abordagem teórica e não pela natureza do objeto. O rizoma, portanto, apresenta-se contrário à estrutura, visto que essa se constitui como 
[...] uma antigenealogia. É uma memória de curto-prazo, ou anti-memória. O rizoma opera por variação, expansão, conquista, captura, ramificações. [...] $\mathrm{O}$ rizoma pertence a um mapa que deve ser produzido, construído, um mapa que é sempre destacável, conectável, reversível, modificável, possui várias entradas e saídas e suas próprias linhas de fuga (DELEUZE; GUATTARI, 2005, p. 21, tradução livre).

No rizoma, os conceitos são concebidos relacionados a circunstâncias e não mais a essências (DELEUZE, 1995), “o conceito é um tijolo" que serve a múltiplos tipos de construção (MASSUMI, 2005, p. xi). O rizoma tem como foco a criação de novas alternativas e caminhos para interpretação conceitual no lugar da complacência teórica às tradições de pensamento. Por isso, o papel da filosofia, mas mesmo o do investigador enquanto operador dentro de um rizoma - em contraposição a sistema -, é de produzir novos conceitos. Os filósofos

[...] não devem mais aceitar conceitos como dádivas, e simplesmente os
purificar e polir, mas, primeiramente, devem criá-los, apresentá-los, torná-los
convincentes. Até agora, tinha-se confiança nos conceitos como se fossem um
dote maravilhoso vindo de algum país das maravilhas. Contudo, [conceitos]
são, afinal, herança de nossos antepassados mais remotos, os mais tolos e
também os mais inteligentes. O que é necessário, acima de tudo, é um
ceticismo absoluto em relação a todos os conceitos herdados (NIETZSCHE,
1967, p. 220-221, 409, tradução livre).

5 Da oposição binária ao estranhamento: abordagens possíveis para a liminaridade

No final do século XX, em desdobramentos de questionamentos que já vinham sendo desenhados desde décadas anteriores, propostas surgiram no sentido de desconstruir ou reposicionar teorias sociológicas e de epistemologia social do ponto de vista dos sujeitos 'fora da norma' ou 'minoritários'. Especificamente, como ferramenta analítica que se sobressaiu a partir de 1990, aparece a teoria Queer. Queer pode ser entendido "por estranho, talvez ridículo, excêntrico, raro, extraordinário. Mas a expressão também se constitui na forma pejorativa com que são designados homens e mulheres homossexuais" (LOURO, 2001, p. 546). O termo, embora com essa carga de deboche, foi apropriado por uma parte de movimentos homossexuais, cuja finalidade é evidenciar uma perspectiva de resistência e contestatória, em um sentido de reapropriação do termo e ressignificação da linguagem (LOURO, 2001).

O empreendimento da teoria Queer nasce pela compreensão da sexualidade humana como construção histórico-social, e pela crítica ao uso da norma majoritária (no caso, heterossexualidade) como crivo para julgar e compreender as subjetivações minoritárias (por exemplo, homossexual). As consequências dessa crítica se estendem para além da análise e compreensão da sexualidade humana, e abalaram a "lógica 
minorizante dos estudos socioantropológicos em favor de uma teoria que questionasse os pressupostos normalizadores que marcavam a sociologia canônica" (MISKOLCI, 2009, p. 151). Essa abordagem preconiza o reconhecimento do sujeito como em constante processo de construção, 'provisório', em rompimento com a tradição cartesiana (MISKOLCI, 2009). Os sujeitos (seus corpos) nunca se conformam totalmente às normalizações a eles impostas, o que produz novas possibilidades que, com efeito, contestam a própria normalização e abrem espaço para novos modos de compreensão que não 'naturalizam' os constructos sociais (BUTLER, 1993).

Os elementos epistemológicos principais da teoria Queer derivam da extensão dos princípios do pós-estruturalismo francês, especialmente de Foucault e Derrida, para além das imediatas reformulações conceituais, incluindo questionamentos ontológicos. Miskolci resume os questionamentos ontológicos dessa "empreitada teórica mais ambiciosa do que a empreendida até então pelas ciências sociais” (MISKOLCI, 2009, p.152) em dois aspectos. Primeiramente, sob influência de Foucault, o questionamento do binômio restritivo normal/desviante no estudo das sexualidades para passar a vê-las como características que se apresentam na experiência humana. Em segundo lugar, sob influência de Derrida, o movimento da desconstrução do binômio pela compreensão de que o 'outro' necessariamente já está dentro de um sistema que define o 'eu' como aquele que não é aquilo que o outro é. Essa é a noção que Derrida chamou de suplementaridade, e como ferramenta analítica ajuda a revelar como os dois 'polos' das construções sociais binárias estão contidos um no outro (MISKOLCI, 2009).

O panorama apresentado de que o discurso da norma se utiliza da noção de desviante para se caracterizar socialmente criou e expandiu categorizações acerca de 'espécies' ou 'tipos' - para o caso específico representado no nascimento da teoria Queer - de sexualidade. De maior interesse nesse processo, para os propósitos do presente artigo, é importante notar que, uma vez que ambos, 'normal' e 'desviante', estão mutuamente imbricados no discurso, é possível revertê-lo estrategicamente de modo que revele sua construção (LOURO, 2001).

Butler, importante figura da área Queer, também mostra que a determinada posição que o sujeito ocupa dentro das possibilidades permitidas em uma comunidade é imprescindível às definições que lhe são contrastantes. Os lugares que habitamos em virtude do reconhecimento a nós direcionado pelo olhar do outro, enquanto processo de construção social, têm fronteiras com os lugares que são inabitáveis para nós (BUTLER, 1993; LOURO, 2001; SALIH, 2002). A identificação dessas fronteiras é parte 
fundamental de um processo de desconstrução de tais construtos sociais para compreensão de um sujeito, enquanto participante de pesquisa.

Nesse sentido, a proposta Queer contém um teoria e uma política pós-identitárias (LOURO, 2001) ao destacarem o fato de que uma política de identidade pode se transformar em aliada do sistema contra o qual ela pretende se rebelar (BUTLER, 1999). O foco dessa política e dessa teoria encontra-se na crítica às oposições binárias aplicadas à sexualidade, deixando de serem concebidas como categorias primordiais que estruturam as práticas sociais. Assim, o pensamento Queer não se limita aos estudos de identidade e sexualidade, ele pode ser expandido (LOURO, 2001), ou seja, pode tornar-se ferramenta de conhecimento produzido por meio dos processos de desconstrução epistemológica de constructos sociais. Mais especificamente, a teoria se debruça na desconstrução do processo pelo qual alguns sujeitos se tornam normalizados e outros marginalizados. Ao desconstruir a naturalização dos binários ou binômios sociais a abordagem Queer permite "pensar a ambiguidade, a multiplicidade e a fluidez das identidades". Permite também novas formas de olhar "a cultura, o conhecimento, o poder" (LOURO, 2001, p. 550). No nosso entender, essa forma de olhar pode ser estendida também às populações vistas como à margem, no que pesa a 'carga desviante' e de 'estranheza' que lhe são atribuídas dentro e fora de seus contextos ou lugares. Dentro da prisão, por exemplo e especialmente, esse é um corpo de conhecimento útil a lidar com esse 'espaço de múltiplas segregações' (COLARES; CHIES, 2010, p. 409).

\section{Desconstruindo e reconstruindo...}

Se utilizamos a desconstrução de constructos sociais como estratégia analítica em pesquisa, o que sobra? Para, tentativamente, responder a esse questionamento, é necessário compreender quais as condições de produção de conteúdo em qualquer método de pesquisa que se utilize, mas especialmente em se tratando de métodos qualitativos que usualmente dependem em grande parte de relatos autobiográficos ou autorreferentes obtidos em condições de entrevista (DE FINA; PERRINO, 2011). Mesmo em métodos mais densamente etnográficos, como a observação participante, não é raro encontrar definições metodológicas que separem - artificialmente - ação de contexto (GIL, 2008), e descrevam o segundo sob o viés do pesquisador-câmera 'neutro' (GEERTZ, 1973), olhando apenas para os detalhes mais imediatos e pontuais do ambiente ou alguma percepção social mais patente. 
O que é necessário é uma compreensão mais aprofundada do contexto em que a informação é produzida. Não basta apenas, por exemplo, mensurar tempo de fala, adequar ambientes, listar questões cruciais, chamar o que se faz de 'entrevista' e dar o assunto por resolvido. A proposta aqui defendida é a de que olhemos para os contextos das relações sociais em ação e interação ao longo de todo o processo desde a formulação das primeiras perguntas de pesquisa, passando pela interação com participantes em si, até o momento das análises, sejam elas quais forem (por exemplo, BORDIEU, 1996; GUERIN, 2016; MEAD, 1972). Essas relações podem ser entre pesquisador(es) e participante(s); entre participante(s); entre participante(s) e outros membros de sua comunidade; e usualmente implicam complexidade material, de poder, de redes sociais, de linguagem, entre outras características. A ideia principal é produzir descrições e compreensões as mais completas possíveis, abandonando a ideia de observador neutro, compilando observações contextuais, sem que se enveredem pelo caminho de uma doxografia (SOUZA, 2012) ou detalhamentos sem-fim, mas que o informem análises verdadeiramente contestadoras das preconcepções acerca dos sujeitos.

\begin{abstract}
Nossas práticas de pesquisa são performáticas, pedagógicas e políticas. Por meio de nossa escrita e fala nós interpretamos [como em uma peça de teatro] os mundos que estudamos. Essas performances são bagunçadas e pedagógicas. Elas instruem nossos leitores sobre o mundo e como nós o vemos. A pedagogia é sempre moral e política; ao interpretar um modo de ver e ser, isto desafia, contesta ou endossa os modos oficiais e hegemônicos de ver e representar o outro (DENZIN, 2006, tradução livre).
\end{abstract}

Estamos, portanto, desafiando ou endossando modos hegemônicos de pensamento? Usualmente, tais questionamentos ficam relegados a subtópicos de seções de metodologia ao invés de figurar no centro de uma densa reflexão metodológica acerca de como o conhecimento é produzido, que lugar ocupa quem está fazendo a pesquisa, quem está participando, e, mais especificamente, como fazer com que os produtos finais da pesquisa efetivamente desafiem a ordem vigente dos constructos sociais e tenha como efeito, ainda que colateral, algum avanço na direção da emancipação e reposicionamento do sujeito 'estranho', 'marginal' ou que habita regiões sociais de liminaridade.

Vale lembrar que, além das justificativas epistemológicas e metodológicas aqui apresentadas, é também responsabilidade dos pesquisadores brasileiros em ciências humanas e sociais o comprometimento com a emancipação de sujeitos no sentido da "recusa de todas as formas de preconceito" e também de "não criar, manter ou ampliar situações de risco [...] ou acentuar estigma, preconceito, discriminação" (BRASÍLIA, 2016, Art $3^{\circ}:$ V, IX). 


\section{Considerações finais: Transferindo as estratégias de desconstrução para o estudo do objeto}

Considerando as abordagens que foram expostas no presente artigo, temos que: a) é possível encontrar o binarismo como estrutura de pensamento e formação de construtos sociais em diversos grupos sociais e isso aponta para uma possível característica estruturante deste tipo de operação lógica para a criação de categorias sociais, ainda que não seja a única operação lógica presente nesses casos; b) as categorias sociais estabelecidas por oposição ou alteridade, tendem, ao longo do tempo, a formatar os diferentes lugares sociais de modo que ambos os polos do binômio se definam mutuamente; c) considerando epistemologicamente o processo de construção de categorias sociais, alguns teóricos propuseram estratégias de desconstrução das hierarquias encontradas e revelaram que as lógicas binárias em si também podem ser subvertidas e substituídas pelas lógicas múltiplas; d) em resumo, juntando todos esses elementos, temos algumas implicações para a práxis de pesquisa, uma vez que todos os sujeitos envolvidos num empreendimento de produção de conhecimento (pesquisador ou pesquisado) são ocupantes de lugares sociais (provisórios) que precisam ser desafiados a fim de compreender o outro de maneira mais completa ou holística e com menos vieses produzidos pelas preconcepções tradicionais.

A desconstrução é assim entendida não como niilismo, mas como uma etapa indissociável da criatividade e inovação, de um processo de desorganização necessária à renovação, no caso, a uma ampliação de perspectiva e aproximação do outro. Nesse exercício de alteridade, de busca por um caminho que conduza à perspectiva do outro ou, pelo menos, a aspectos um pouco mais autênticos -, depara-se com os sempre presentes desafios da comunicação.

Diante de panorama apresentado acima, seguem algumas sugestões de ações de planejamento e implementação de pesquisa qualitativa que podem ser adotadas por pesquisadores no sentido de mitigar os vieses que se busca evitar e majorar a influência dos contextos e relações sociais na análise de dados subsequente ao momento de coleta de dados. Diante do desafio de formatar uma prática que efetivamente produza dados inovadores, alguns autores já enunciaram certas sugestões de como proceder de modo a desestabilizar, desconstruir ou mitigar a influência das preconcepções tradicionais no momento da pesquisa. 
Como Wendell Johnson já identificava (1951), há um longo percurso físico e intersubjetivo entre o falado e o não dito. Podemos dizer que existe uma distância material e imaterial entre o que é articulado e o que se possa referir como "intenção" de comunicação, entre o que é dito por alguém e o que e como isso é compreendido por quem recebe a mensagem. Nesse caminho, interpõem-se como obstáculos, ou 'ruídos', aspectos típicos de uma comunicação mediada e as subjetividades de quem se expressa e de quem é alcançado pelo fruto dessa expressão. Além de outras inúmeras propriedades relacionais dos discursos que não se limitam a processos de comunicação, apenas. Levando tais considerações ao extremo e adotando uma interpretação bergsoniana, podese dizer que toda comunicação é mediada - mesmo quando se trata de algo dito em viva voz diretamente ao interlocutor, sem a intermediação de qualquer aparato físico - e que a comunicação total e efetiva não é possível, mas idealizada.

Assim, é preciso estarmos atentos aos entraves já conhecidos e às armadilhas próprias do processo comunicacional. Construtos, por exemplo, podem ser incluídos no campo de ação desse alerta. Tanto construtos elaborados como metáfora para ampliar a efetividade da comunicação, como construtos decorrentes de estigmatizações e marginalizações. Mesmo tendo-se consciência do alcance dessas interferências positivas e negativas, não se pode lidar com os construtos como fatos consumados, ou padrões de referência que determinam de forma inequívoca o 'desempacotamento' de uma mensagem, trazida à consciência do outro pelo desencadeamento dos processos que a acolhem e a interpretam.

Todos esses aspectos não estão confinados estritamente ao campo de estudo das ciências da comunicação. O acesso à informação e os efeitos do discurso no ouvinte submetem-se, em grande medida, às mesmas interferências processuais e aos fatores considerados tratados pelo interacionismo simbólico (por exemplo, MEAD, 1972). A tentativa de ouvir, contextualizar e interpretar reações e significados das pessoas torna os efeitos desses fenômenos ainda mais sensíveis, principalmente se elas estão confinadas e em condições de vulnerabilidade. Conhecê-los requer a aplicação de métodos apropriados, elencados a partir de uma combinação anímica entre desapego a padrões prontos e flexibilidade para adaptar-se a contextos e necessidades específicas. E os esforços para minimizá-los conduzem a resultados mais favoráveis quando orientados por expedientes metodológicos e atitudes analíticas não ortodoxas.

Guerin (2016) apresenta um apanhado geral de sugestões para desconstruir o olhar sobre os fenômenos em análise de como a produzir uma compreensão contextual dos 
mesmos. É importante, por exemplo, evitar categorizar aquilo que se observa em unidades discretas. Veja que, isso em si já incorpora a noção de desconstrução dos binarismos explicitados acima. Evitar categorizar as ações ou as pessoas em unidades discretas produz informações mais maleáveis e (possivelmente) mais representativas da complexidade real dos grupos humanos. Por exemplo, de que serve dizer, do ponto de vista de um pesquisador em determinado fenômeno social, que certo participante de pesquisa é 'agressivo', ou 'apático', ou 'engajado politicamente', ou 'triste'? Interessa, isso sim, as razões do comportamento rotulado agressivo; como aconteceu; em que contexto ocorreu; direcionado a quem a ação foi iniciada; e - em dado usualmente negligenciado - porque eu, como pesquisador, li essa situação como agressividade.

Produzir uma descrição - com fidedignidade - que desafie as respostas que tradicionalmente são dadas a determinados fenômenos não é um empreendimento que se consegue sem treino, ou sem longa reflexão. É preciso retreinar o olhar, na verdade, para passar a observar dados que de outro modo passariam despercebidos. Por exemplo, a maioria das condições que consideramos como fato estático ou dado são, após um olhar mais criterioso, processos com variações e modificações ao longo do tempo. Tentar observar processos ao invés de objetos é uma das dicas oferecidas por Guerin (2016) a fim de produzir o que o autor chama de observações contextuais. Outras dicas incluem compreender que 'nomear' processos identificados fazem, em geral, com que o pesquisador pare de observar os detalhes dos contextos e relações sociais que investiga. Ou seja, é preciso procurar manter-se observando o maior tempo possível antes de traçar conclusões ou definir outros constructos sociais sobre o fenômeno estudado. Outra sugestão é procurar não observar sozinho. Na direção de dirimir o efeito dos próprios préconceitos do pesquisador, ao compartilhar observações é possível aprender mais e mais completamente acerca dos fenômenos sociais estudados.

O empreendimento de pesquisa deve, portanto, buscar alternativas às ortodoxias e tradições de pensamento quando em contato com populações marginalizadas e/ou minoritárias. Ainda que as visões enviesadas, as armadilhas da comunicação e do discurso e nossos próprios modos de operações lógicas para interpretar 'o outro' sejam fatores em todas as interações de pesquisa e não só com populações 'especiais'. Tais alternativas podem se pautar pela produção, no maior grau possível, de compreensões holísticas e contextuais, seja da pessoa individualmente, seja do grupo ou comunidade. Ao fazer isso, busca-se práticas metodológicas que possam habilitar o pesquisador a efetivamente entrar em contato com o mundo social que habita o sujeito com quem conversa. 
Nesse sentido, a desconstrução pode ser aliada instrumental e paradigmática às atividades de coleta e análise de dados. Pode maleabilizar a formatação do levantamento de dados junto ao objeto de estudo, alertando o pesquisador sobre a presença de construtos, e tornar fluida e dinâmica a análise das informações coligidas, contextualizando significações e identificando vieses. A partir de uma orientação desconstrucionista, o pesquisador analista dota-se de condições que possibilitam isolar vieses e ampliar a observância metodológica da pesquisa em andamento, assumindo até determinado grau de ceticismo. Ceticismo no sentido epistemológico, de questionar o conhecimento, fatos, opiniões e crenças consideradas como fatos propriamente ditos. Nesse caso, o pesquisador põe em dúvida seus próprios sentidos e senso analítico, submetendo-os constantemente a juízo crítico.

Tal expediente analítico pode dialogar com disciplinas e abordagens que apresentam potencial metodológico para remover obstáculos do caminho rumo à perspectiva do outro. Nesse sentido, retomando o exemplo da pesquisa onde nasce a reflexão ora apresentada, foram buscadas múltiplas abordagens que pudessem ajudar a caracterizar participantes, objetivos, direcionamentos e delineamentos metodológicos de pesquisa. Naquele momento - ao pesquisar e não a priori -, foram definidas como influências para a metodologia produzida a hermenêutica, a fenomenologia, a dialética e o interacionismo simbólico (MUNIZ; LEUGI; ALVES, 2017). O aprofundamento da compreensão contextual pôde levar, como decorrência, à proposição de outros passos, incluindo saberes diversos e transdisciplinares não previstos na proposta inicial, por exemplo as ideias de governança participativa, articulação em redes sociotécnicas, cooperação e associação para o trabalho. Tais decorrências para além do escopo inicial alargam os horizontes investigativos e compõem os 'tijolos' de uma 'bricolagem' investigativa (LÉVI-STRAUSS, 2008; KINCHELOE, 2001) que pretende, por definição, construir interpretações que lidem com a complexidade natural dos fenômenos.

Assim, ao configurar métodos e abordagens analíticas balizados por desconstruções estratégicas, busca-se reunir os méritos das orientações interpretativista e crítica, junto às quais a desconstrução pode desempenhar papel relevante para proporcionar uma compreensão mais profunda e contextual da questão em estudo, sobretudo no que se refere à análise da subjetividade das informações. De certa forma, percebe-se quase intuitivamente a combinação integrada da triangulação metodológica assim constituída e dos 'flashes' reveladores e elucidativos proporcionados pela desconstrução, como servindo de 'referencial de perspectiva' ou 'ponto de fuga', mas em 
revezamento constante. A triangulação é um recurso metafórico - mais um construto? para simbolizar a interação entre eixos metodológicos e ilustrar esse movimento de deslocamento e aproximação entre os referenciais que pode ser exercido por uma desconstrução estratégica.

\section{Agradecimentos}

Os autores agradecem ao Conselho Nacional de Desenvolvimento Científico e Tecnológico $(\mathrm{CNPq})$ pelo apoio à realização do presente trabalho, recebido na modalidade de bolsas PCI-DA concedidas aos três primeiros autores.

\section{Referências}

ALVES, A. M.; HOLANDA, G. M. Metodologias 'líquidas': Combinando abordagens e métodos para avaliações de políticas públicas em TIC. Revista Brasileira de Políticas Públicas e Internacionais, João Pessoa, v. 1, n. 2, p. 70-90, dez. 2016.

BAUMAN, Z. Liquid modernity. Cambridge: Polity Press in association with Blackwell Publishing Ltd, 2000.

BENTLEY, A. F. On a certain vagueness in logic: I. The Journal of Philosophy, New York, v. 42, n. 1, p. 6-27, jan. 1945a.

BENTLEY, A. F. On a certain vagueness of logic: II. The Journal of Philosophy, New York, v. 42, n. 2, p. 39-51, jan. 1945b.

BORDIEU, P. Understanding. Theory, Culture \& Society, London, v. 13, n. 2, p. 17-37, may. 1996.

BUTLER, J. Bodies that matter: On the discursive limits of 'sex'. New York; London: Routledge, 1993.

BUTLER, J. Gender trouble: Feminism and the subversion of identity. 2. ed. New York: Routledge, 1999.

BRASÍLIA. Conselho nacional de saúde. Resolução 510/2016. Brasília: Ministério da Saúde, 2016.

CALLIOU, S. Us/them, me/you: Who? (Re)thinking the binary of First Nations and non-First Nations. Canadian Journal of Native Education, Edmonton, v. 22, n. 1, p. 28-52. 1998.

COLARES, L. B. C.; CHIES, L. A. B. Mulheres nas so(m)bras: Invisibilidade, reciclagem e dominação viril em presídios masculinamente mistos. Revista Estudos Feministas, Florianópolis, v. 18, n. 2, p. 407-423, maio./ago. 2010.

COLEBROOK, C. Gilles Deleuze. London; New York: Routledge, 2002.

COSTA, E. C. P. Enfim, a liberdade: As mulheres e a vivência pós-cárcere. 2011. Tese (Doutorado em Sociologia) - Centro de Filosofia e Ciências Humanas, Universidade Federal de 
Pernambuco, Recife, 2011.

DE FINA, A.; PERRINO, S. Introduction: Interviews vs. 'natural' contexts: A false dilemma. Language in Society, London, v. 40, n. 1, p. 1-11, feb. 2011.

DELEUZE, G. On a Thousand Plateaus (1980). In: DELEUZE, G. Negotiations, 1972-1990. Translated by Martin Joughin. New York: Columbia University Press, 1995. p. 25-34.

DELEUZE, G.; GUATTARI, F. A thousand plateaus: Capitalism and schizophrenia. 11. ed. Translated by Brian Massumi. Minneapolis; London: University of Minnesota Press, 2005.

DENZIN, N. K. Analystic autoethnography, or déjà vu all over again. Journal of Contemporary Ethnography, Thousand Oaks, v. 35, n. 4, p. 419-428, August. 2006.

DERRIDA, J. Margens da filosofia. Tradução de Joaquim Torres Costa e Antonio M. Magalhães. Campinas: Papirus, 1991.

DOUGLAS, M. Natural symbols: Explorations in cosmology. 3. ed. London; New York: Routledge, 2002.

DURKHEIM, É.; MAUSS, M. Algumas formas primitivas de classificação: contribuição para o estudo das representações coletivas. In: RODRIGUES, J. A. (org.). Émile Durkheim. 9. ed. São Paulo: Ática, 2000. p. 183-203.

GEERTZ, C. The interpretation of cultures: Selected essays. New York: Basic Books, Inc., 1973.

GIL, A. C. Métodos e técnicas de pesquisa social. 6. ed. São Paulo: Atlas, 2008.

GUERIN, B. How to rethink human behavior: A practical guide to social contextual analysis. London: Routledge, 2016.

GUIMARÃES, C. A. G. Funções da pena privativa de liberdade no sistema penal capitalista: Do que se oculta(va) ao que se declara. 2006. Tese (Doutorado em Direito) - Centro de Ciências Jurídicas, Universidade Federal de Santa Catarina, Florianópolis, 2006.

HERTZ, R. A preeminência da mão direita: Um estudo sobre a polaridade religiosa. Religião e Sociedade, Rio de Janeiro, n. 6, p. 99-128, nov. 1980.

JOHNSON, W. The spoken word and the great unsaid. The Quarterly Journal of Speech, Washington, v. 37, n. 4, p. 419-429, 1951.

KINCHELOE, J. L. Describing the bricolage: Conceptualizing a new rigor in qualitative research. Qualitative Inquiry, Thousand Oaks, v. 7, n. 6, 679-692, dec. 2001.

KUPER, A. (org.). The social anthropology of Radcliffe-Brown. London; Henley; Boston: Routledge \& Kegan Paul, 1977.

LÉVI-STRAUSS, C. Origem dos modos à mesa. Mitológicas 3. São Paulo: Cosac Naify, 2006.

LÉVI-STRAUSS, C. O pensamento selvagem. 8. ed. Campinas: Papirus, 2008.

LOURO, G. L. Teoria queer: Uma política pós-identitária para a educação. Revista Estudos Feministas, Florianópolis, v. 9, n. 2, p. 541-553. 2001. 
MASSARO, C. M. Trabalho em tempos de crise: A superexploração do trabalho penal nos Centros de Ressocialização Femininos do Estado de São Paulo. 2014. Tese (Doutorado em Ciências Sociais) - Faculdade de Ciências e Letras, Universidade Estadual Paulista 'Júlio de Mesquita Filho', Araraquara, 2014.

MASSUMI, B. Translator's foreword: Pleasures of philosophy. In: DELEUZE, G; GUATTARI, F. A thousand plateaus: Capitalism and schizophrenia. 11. ed. Minneapolis; London: University of Minnesota Press, 2005. p. ix-Xv.

MEAD, G. H. Mind, self, and society: From the standpoint of a social behaviorist. 18. ed. Chicago; London: The University of Chicago Press, 1972.

MISKOLCI, R. A teoria queer e a sociologia: O desafio de uma analítica da normalização. Sociologias, Porto Alegre, n. 21, p. 150-182, jan./jun. 2009.

MUNIZ, C. R.; LEUGI, G. B. Pensando políticas públicas de reintegração social pós-cárcere. In: ALVES, A. M.; HOLANDA, G. M.; PEREIRA, C. M. (orgs.). Metodologias poli. TIC: Avaliando políticas digitais. Campinas: CTI Renato Archer, 2018. p. 139-162.

MUNIZ, C. R.; LEUGI, G. B.; ALVES, A. M. Mulheres no sistema prisional: Por que e como compreender suas histórias? RP3 - Revista de Pesquisa em Políticas Públicas, Brasília, n. 2, p. 1-22. 2017.

NIETZSCHE, F. The will to power. Tradução de Walter Kaufmann e Reginald John Hollingdale. New York: Vintage Books, 1967.

PHILOGÈNE, G. Social representations of alterity in the United States. In: MOLONEY, G.; WALKER, I. (org.). Social representations and identity: Content, process, and power. New York: Palgrave Macmillan, 2007. p. 31-42.

RADCLIFFE-BROWN, A. R. Structure and function in primitive society: Essays and addresses. Glencoe: The Free Press, 1952.

SALIH, S. Judith Butler. London; New York: Routledge, 2002.

SOUZA, R. M. Rizoma Deleuze-Guattariano: Representação, conceito e algumas aproximações com a educação. Revista Sul-Americana de Filosofia e Educação, Brasília, n. 18, p. 234-259, maio./out. 2012.

Recebido em: 22 de fevereiro de 2018.

Aceito em: 07 de março de 2019. 